\begin{tabular}{|l|l|}
\hline Postprint Version & Final draft post-refereeing \\
\hline Journal website & $\underline{\text { http://www.springerlink.com/content/101494/ }}$ \\
\hline Pubmed link & $\underline{\text { http://www.ncbi.nlm.nih.gov/pubmed/19305935 }}$ \\
\hline DOI & $\underline{10.1007 / \text { s00127-009-0035-3 }}$ \\
\hline
\end{tabular}

\title{
ADVERSE LIFE EVENTS AMONG COMMUNITY-DWELLING PERSONS AGED 65-70 YEARS: GENDER DIFFERENCES IN OCCURRENCE AND PERCEIVED PSYCHOLOGICAL CONSEQUENCES
}

Seematter-Bagnoud Laurence, MD, MSc, Karmaniola Athanassia, PhD, Santos-Eggimann Brigitte, MD, MPH, DrPH.

\author{
Affiliation: \\ Health Services Unit \\ Institute of Social and Preventive Medicine \\ University of Lausanne, Switzerland \\ Corresponding author: \\ Laurence Seematter-Bagnoud \\ Unité des services de santé \\ Institut Universitaire de Médecine Sociale et Préventive \\ Route de Berne 52 \\ CH-1010 Lausanne, Switzerland. \\ Tel: + 41213149793 \\ Fax: +41213149767 \\ Email: Laurence.Seematter-Bagnoud@chuv.ch
}

\begin{abstract}
Objectives: to describe the occurrence of selected adverse life events in young-old men and women, as well as their perceived psychological consequences.

Methods: In 2005, 1422 participants in the Lausanne Cohort 65+ study, born in 1934-1938, self-reported whether they experienced any of 26 life events during the preceding year. Most participants ( $\mathrm{N}=1309,92 \%)$ completed the Geriatric Adverse Life Events Scale (GALES) during a face-to-face interview, by rating the level of stress associated with each event, as well as its impact on their psychological well-being.

Results: Overall, $72 \%$ of the participants experienced at least one of the 26 events in the preceding year (range: 1-9). Disease affecting the respondent $(\mathrm{N}=525)$ or a close relative $(\mathrm{N}=276)$ was most frequent, as well as the death of a friend or non-close relative $(\mathrm{N}=274)$.

Women indicated a higher frequency of events (mean: 2.1 vs. 1.7 events, $\mathrm{p}<.001$ ), as well as a higher level of stress and a stronger negative impact on well-being than men. In multivariate analyses adjusting for self-rated health, depressive symptoms and comorbidity, female gender
\end{abstract}


remained significantly associated with the level of stress and negative impact on psychological well-being.

Conclusion: This exploratory study shows that several types of adverse life events frequently occur at age 65-70, with gender differences both in the frequency of reporting and consequences of these events. However, information on this topic is limited and studies based on different populations and designs are needed to better understand the impact of such events.

Keywords: life change events, aged, adaptation psychological, gender

\section{INTRODUCTION}

While the occurrence of positive major life events tends to decline with age, some types of adverse events such as the incidence of disease and the loss of a significant relative or friend take place more frequently ${ }^{(1)}$. Despite the potential impact of these experiences on mental and physical health ${ }^{(2-3)}$, few instruments are available for evaluating adverse life events in elderly subjects. We found only one scale that had been specifically designed for elderly persons ${ }^{(3)}$, based on the observation that previously existing instruments either included events not relevant to an older population, lacked relevant items, or were too long. Interestingly, this instrument, the Geriatric Adverse Events Life Scale (GALES), has been the subject of a unique publication ${ }^{(4)}$ which described the occurrence of selected events during the previous 12 months among persons aged 60 years and over, and compared their impact on mood in depressed versus non-depressed subjects. The findings, consistent with a higher level of stress and a stronger negative psychological impact among depressed persons, were considered as evidence of discriminant validity.

Nevertheless, research on this topic remains limited. As an example, a search on Medline, 1980-2008, retrieved 499 publications about life change events, only 10 of which concerned the occurrence and consequences of such events among older persons. The same search conducted on PsycInfo, 1985-2008, found 85 publications, only one of which was relevant. Furthermore, some of these selected publications focused on specific populations (small sample of persons with a specific disease) or settings (hospital, institution), providing little information on the epidemiology of negative events in the general population of older persons. Indeed, much of the literature concentrated on the association with depressive problems ${ }^{(5-8)}$. The role of characteristics that might influence an individual's reaction to adverse life events, such as gender or socio-economic status, has not been widely examined in older persons, although studies conducted among younger age groups have shown that female gender, a lower socio-economic and educational status were associated with a higher psychological effect of such events ${ }^{(9,10)}$.

Therefore, the principal objective of this cross-sectional analysis was to describe the occurrence of recent adverse life events at the age of 65 to 70 years, as well as the stress and psychological impact related to these events. We were also interested in comparing men and women regarding the frequency and perceived consequences of events, and in investigating whether differences in stress and impact remain after adjustment for potential social, educational and medical confounders. 


\section{METHODS}

In Spring 2004, 1422 residents of Lausanne born between 1934 and 1938 enrolled in a study on age-related frailty ${ }^{(11)}$ and answered a postal questionnaire that included part of the Geriatric Adverse Events Life Scale $\left(\mathrm{GALES}^{4}\right)$ : they reported whether they experienced any of 26 life events during the preceding year and how many times the event occurred. Most of the participants ( $\mathrm{N}=1309,92 \%)$ then participated in a face-to-face interview during which the GALES was completed. First, their answers were checked by the research assistant to confirm whether each reported life event indeed occurred within the specified time-frame. Participants then had to rate the level of stress associated with each type of event on a 3-point scale (not at all, somewhat, or very stressful), as well as its impact on their psychological well-being on a 5-point scale (felt much better, better, the same, worse, or much worse). These ratings took into account the number of times each type of event occurred: for example, a participant who reported the loss of two friends had to rate the stress and impact associated with both bereavements taken together.

\section{Statistical analyses}

First, the distribution of life events reported by men and women was examined, as well as the mean number of events reported in each gender for the preceding 12 months. Next, the distribution of levels of stress and impact on psychological well-being associated with each type of event was compared in men and women. The sum of scores across all types of events was computed for both perceived stress and impact on well-being. The mean levels of cumulated stress and impact were compared in men and women. Since the aim of this work was exploratory, we did not adjust for multiple comparisons, and p-values are to be taken as indicative.

Finally, the association between gender and life events-related stress and impact was examined in multivariate analyses, adjusting for living alone, self-rated health, depressive symptoms, comorbidity and educational level. Two linear regression models were computed, the first for the association between gender and stress, the second for the association between gender and impact on well-being.

\section{RESULTS}

Participants were homogeneously distributed over the five years of birth, and fifty-nine percent of participants were women (Table 1). About half of the participants were married, while one in three was either divorced or widowed, and one in three lived alone. Men were more likely to be married and less likely to live alone. A large majority of men and women rated their health as good or very good, although women more frequently reported two or more chronic diseases. The reporting of depressive symptoms, diagnosed or treated depression was also more frequent among women.

About a quarter of the participants (28\%) did not report any of the 26 types of adverse events during the preceding year, sixty percent experienced 1 to 3 types of events, and about one in ten participants (12\%) experienced as many as 4 to 9 types of events during the last 12 months. The mean number of types of events was 1.6, while the median was 1 . Participants had to indicate how many times they experienced each type of event that occurred during the previous year. Thus, the mean total number of events experienced during the last year was 2.0 (range 0-23), with a median also equal to 1 . Most frequently reported events were physical illnesses: onset of a new illness $(\mathrm{N}=259)$, existing disease $(\mathrm{N}=266)$, and illness of close family members $(\mathrm{N}=276)$. The death of a friend or non-first degree relative was also a frequently 
reported event $(\mathrm{N}=274)$. Several participants became caretakers for relatives or friends $(\mathrm{N}=169)$. Major financial difficulties were encountered by 110 participants, while 146 reported major family conflicts other than with spouse. Other major traumatic events such as deaths of first degree relatives (spouse, parents, child) and divorce were less frequently reported.

Table 2 describes the frequency of the 26 adverse events in men compared to women. Women consistently reported a higher frequency of events, with an average of 2.1 events during the last year, as compared to a mean of 1.7 events in men. A marked gender difference in the occurrence of events was found only for a few events, namely physical illness of a close family member, accident or injury, separation from a close friend or relative other than spouse/partner, and death of pet, which were more frequently reported by women.

The distribution of levels of stress and impact on psychological well-being is displayed for each type of event in Table 3, separately for men and women. Women tended to report a higher level of stress for almost every event, except retirement, death of spouse, and voluntary change of place of residence. The mean level of cumulated stress was higher in women than in men (3.59 vs. 2.62, $\mathrm{p}<.001$ ). In particular, women indicated a higher level of stress than men for illnesses affecting themselves, close relatives or friends, and for non-marital conflicts.

Regarding the impact on psychological well-being, men more often reported that the event had little impact on their well-being, while women more often reported a strong negative impact. As a consequence, the mean level of cumulated negative impact was higher in women than in men (6.74 vs. 5.24, $\mathrm{p}<.001)$. A few events tended to be rated more negatively by men: marital difficulties, death of spouse, death of parents, being forced to leave home and having an individual moving into/out of the household were associated with a higher negative impact on well-being, although not to a statistically significant extent, in men as compared to women. By contrast, a few events were not infrequently rated as having had a positive effect on wellbeing. In particular, getting divorced or breaking up a long-term relationship, as well as moving, sometimes resulted in an improved psychological well-being. Becoming a caretaker also occasionally had a positive effect. Finally, in women, the death of a spouse or the death of a parent was associated with improved well-being in some cases, although this was not the case in men.

In multivariate analyses (Table 4), female gender remained positively and significantly associated with the level of stress and the level of negative impact on psychological wellbeing. Perceiving own health as fair or poor, reporting depressive symptoms or depression or having two or more chronic diseases were all positively associated with both level of stress and negative impact. The relationship between the level of educational status and the level of stress, respectively of impact, showed a positive trend, indicating an increasing stress and negative impact with higher educational level. The association was significant in the higher education groups only. 


\section{CONCLUSIONS}

About three out of four young-old persons in our study experienced at least one of 26 adverse events during the past year, with a higher frequency among women, as previously reported ${ }^{(10 \text {, }}$ ${ }^{12)}$. Since the GALES instrument involves a selection of relevant important negative events such as diseases and deaths, the occurrence of over- or under-reporting due to forgetfulness is unlikely. Indeed, a one year time frame has been considered as appropriate for obtaining a reasonable estimate of variations in exposure to recent life events, but short enough to avoid a substantial decline in the ability to recall the events ${ }^{(13)}$. Moreover, the self-completed instrument was then checked by the research assistant during a face-to-face interview. There are two plausible explanations for the gender difference in the frequency of self-reported life events. First, women are more likely to experience the death of a spouse or friend because of their longer life expectancy as compared to men, and because women in this generation tend to marry men who are older than themselves. Second, the possibility that women are more likely to report their diseases or other adverse events than men cannot be ruled out ${ }^{(14)}$. However, although women are known to be more likely to suffer from chronic diseases ${ }^{(15,16)}$, we observed no difference in the frequency of incident physical illnesses in men and women, but only in the frequency of any accident or injury in the previous year. Finally, women more frequently reported becoming caretakers for a relative or friend, which might be linked to their longevity or to their social role.

As women more often reported factors associated with a greater burden of negative events, such as depressive symptoms, a lower education level, or chronic diseases, we examined the relationship between female gender and life events-related stress and impact in multivariate models. For both stress and impact, a significant independent association was found with female gender. This finding is consistent with previous studies. As an illustration, research on the scaling of life change events has illustrated profound differences between men and women in the scaling of similar events ${ }^{(17)}$. The comparison of men's and women's levels of stress and psychological impact for each type of event has to be taken as indicative for two reasons. First, the low frequency of reporting of several events, such as deaths, might be responsible for the lack of statistical power in these comparisons. Second, some statistically significant differences might be attributable to the numerous comparisons. However, the observed tendencies correspond to previous findings. In particular, men have been observed to be less able to cope with the death of a spouse ${ }^{(18)}$.

The GALES might be criticized, in particular regarding the inclusion of existing diseases in the list of negative events, although they might not be considered as events in the sense of discrete occurrences. This inclusion might however well be justified considering that a chronic disease, such as cardiovascular disease, might cause stress and other psychological consequences on the long term, in particular because of periods of exacerbation. Our results confirm the impact of these diseases on well-being in a older population. Then, the checklist format of the GALES allows to gather a limited amount of information as compared to qualitative research. A checklist approach nevertheless allows to collect standardized information on significant events in the context of quantitative studies not dedicated to the topic of life events, to examine their relationship with health, and to take them into account when studying health outcomes.

In conclusion, this descriptive work highlights the frequency and perceived consequences of adverse life events in the general population of older persons, even at the beginning of old age. The Lausanne Cohort 65+ study will allow us to further study the impact of such events longitudinally, and, in particular, their association with age-related frailty. 
Acknowledgment: we thank the persons who enrolled in the Lc65+ study, and the Loterie Romande (non-profit organization supporting research and social projects) for their grant to the Fondation Lausanne cohorte Lc65+.

\section{References}

1. Hughes DC, Blazer DG, George LK. Age differences in life events: a multivariate controlled analysis. Int J Aging Hum Dev 1988;27:207-220.

2. Hardy SE, Concato J, Gill TM. Stressful life events among community-dwelling older persons. J Gen Intern Med 2002; 17:841-847.

3. Moos RH, Brennan PL, Schutte KK et al. Older adults' coping with negative life events: common processes of managing health, interpersonal, and financial/work stressors. Int J Aging Hum Dev. 2006;62:39-59.

4. Devanand DP, Kim MK, Paykina N, Sackeim HA. Adverse life events in elderly patients with major depression or dysthymic disorder and in healthy-control subjects. Am J Geriatr Psychiatry 2002; 10:265-274.

5. Kessing LV, Agerbo E, Mortensen PB. Does the impact of major stressful life events on the risk of developing depression change throughout life? Psychological Medicine 2003; 33:1177-1184.

6. Glass TA, Kasl SV, Berkman LF. Stressful life events and depressive symptoms among the elderly. Evidence from a prospective cohort study. J Aging Health 1997; 9:70-89.

7. Fountoulakis KN, Iacovides A, Kaprinis S, Kaprinis G. Life events and clinical subtypes of major depression: a cross-sectional study. Psychiatry Research 2006; 143:235-244.

8. Moos RH, Schutte KK, Brennan PL, et al. The interplay between life stressors and depressive symptoms among older adults. J Gerontol B Psychol Sci Soc Sci. 2005; 60:P199-206.

9. Miller MA, Rahe RH. Life changes scaling for the 1990s. J Psychosom Res 1997; 43:279-292.

10. Dalgard OS, Dowrick C, Lehtinen V et al. Negative life events, social support and gender difference in depression. Soc Psychiatry Psychiatr Epidemiol 2006; 41:444451.

11. Santos-Eggimann B, Karmaniola A, Seematter-Bagnoud L et al. The Lausanne cohort Lc65+: a population-based prospective study of the manifestations, determinants and outcomes of frailty. BMC Geriatrics (submitted).

12. Kendler KS, Thornton LM, Prescott CA. Gender differences in the rates of exposure to stressful life events and sensitivity to their depressogenic effects. Am J Psychiatry. 2001 Apr;158(4):587-93.

13. Turner RJ, Wheaton B in: Measuring stress: a guide for health and social scientist. Ed. By S Cohen, RC Kessler, L Underwood Gordon. Oxford University Press, New York, 1995.

14. Verbrugge L, Wingard D. Sex differentials in health and mortality. Women and Health 1987; 12:103-145.

15. McDonough P, Walters V. Gender and health: reassessing patterns and explanations. Soc Sci Med 2001; 52:547-559. 
16. Hardy SE, Concato J, Gill TM. Stressful life events among community-living older persons. J Gen Intern Med 2002; 17:841-847.

17. Miller MA, Rahe RH. Life changes scaling for the 1990s. J Psychosom Res. 1997 Sep;43(3):279-92.

18. Blazer DG. Life events, mental health functioning, and the use of health care services by the elderly. Am J Public Health 1980; 70:1174-1179. 
Seematter-Bagnoud L, Karmaniola A, Santos-Eggimann B. Adverse life events among community-dwelling persons aged 6570 years: gender differences in occurrence and perceived psychological consequences. Social Psychiatry and Psychiatric Epidemiology 2010;45(1):9-16.

Table 1 : Description of the study population, by gender ( $\mathrm{N}=1422)$

\begin{tabular}{|c|c|c|c|c|}
\hline Variable & $\begin{array}{c}\text { Total } \\
\text { population } \\
(\mathrm{N}=1422, \%)\end{array}$ & $\begin{array}{c}\text { Men } \\
(\mathrm{N}=582, \%)\end{array}$ & $\begin{array}{c}\text { Women } \\
(\mathrm{N}=840, \%)\end{array}$ & P value* \\
\hline \multicolumn{5}{|l|}{ Civil status : } \\
\hline Married & 57.8 & 74.9 & 45.9 & $<.001$ \\
\hline Widowed & 13.0 & 4.1 & 19.1 & \\
\hline Single & 11.4 & 7.7 & 14.0 & \\
\hline Divorced & 17.8 & 13.2 & 20.9 & \\
\hline Living alone & 35.0 & 18.8 & 46.3 & $<.001$ \\
\hline \multicolumn{5}{|l|}{ Education : } \\
\hline Compulsory schooling only & 25.9 & 18.1 & 31.3 & .000 \\
\hline Apprenticeship & 39.7 & 42.8 & 37.5 & \\
\hline Post-compulsory schooling & 22.8 & 20.5 & 24.3 & \\
\hline Tertiary education & 11.6 & 18.5 & 6.9 & \\
\hline \multicolumn{5}{|l|}{ Self-rated health : } \\
\hline Very good/good & 63.7 & 65.8 & 62.2 & .171 \\
\hline Fair/Poor/very poor & 36.3 & 34.2 & 37.8 & \\
\hline Chronic diseases : 2 or more & 64.7 & 60.1 & 67.9 & .003 \\
\hline Depressive symptoms & 25.3 & 19.7 & 29.3 & $<.001$ \\
\hline
\end{tabular}

* P-value from chi-squared test 

psychological consequences. Social Psychiatry and Psychiatric Epidemiology 2010;45(1):9-16.

Table 2 : Occurrence of adverse life events during the previous 12 months, by gender

\begin{tabular}{|c|c|c|c|c|c|}
\hline \multirow[t]{2}{*}{ Adverse life events } & \multicolumn{2}{|c|}{$\begin{array}{c}\text { Men } \\
(\mathrm{N}=582)\end{array}$} & \multicolumn{2}{|c|}{$\begin{array}{l}\text { Women } \\
(\mathrm{N}=840)\end{array}$} & \multirow[t]{2}{*}{ P-value * } \\
\hline & $\mathrm{n}$ & $\%$ & $\mathrm{n}$ & $\%$ & \\
\hline \multicolumn{6}{|l|}{ Financial/work difficulties } \\
\hline Financial difficulties & 43 & 7.4 & 67 & 8.0 & .778 \\
\hline Retirement & 19 & 3.3 & 15 & 1.8 & .178 \\
\hline Loss of employment & 3 & 0.5 & 3 & 0.4 & .786 \\
\hline $\begin{array}{l}\text { Physical illness/accident } \\
\text { New major physical illness }\end{array}$ & 96 & 16.5 & 163 & 19.4 & .301 \\
\hline Other major physical illness & 97 & 16.7 & 169 & 20.1 & .204 \\
\hline Physical illness of close family member & 92 & 15.8 & 184 & 21.9 & .012 \\
\hline Accident/injury & 40 & 6.9 & 97 & 11.6 & .010 \\
\hline \multicolumn{6}{|l|}{ Interpersonal conflicts } \\
\hline Marital separation/divorce & 8 & 1.4 & 6 & 0.7 & .408 \\
\hline Other marital difficulties & 29 & 5.0 & 37 & 4.4 & .771 \\
\hline
\end{tabular}




\begin{tabular}{|c|c|c|c|c|c|}
\hline $\begin{array}{l}\text { Major family problems/conflicts other than with } \\
\text { spouse }\end{array}$ & 52 & 8.9 & 94 & 11.2 & .318 \\
\hline Major problems/conflicts with friends/neighbours & 18 & 3.1 & 29 & 3.5 & .803 \\
\hline $\begin{array}{l}\text { Break-up of long-term relationship other than } \\
\text { marriage }\end{array}$ & 6 & 1.0 & 13 & 1.6 & .606 \\
\hline Separation from other close friend/relative & 4 & 0.7 & 31 & 3.7 & .001 \\
\hline \multicolumn{6}{|l|}{ Interpersonal loss } \\
\hline Death of spouse & 3 & 0.5 & 9 & 1.1 & .455 \\
\hline Death of child & 3 & 0.5 & 3 & 0.4 & .786 \\
\hline Death of parent & 16 & 2.8 & 28 & 3.3 & .705 \\
\hline Death of brother/sister & 25 & 4.3 & 28 & 3.3 & .568 \\
\hline Death of other relative/close friend & 106 & 18.2 & 168 & 20.0 & .580 \\
\hline Death of pet & 11 & 1.9 & 40 & 4.8 & .013 \\
\hline \multicolumn{6}{|l|}{ Disruption in living situation } \\
\hline Forced to leave/lose home & 5 & 0.9 & 4 & 0.5 & .586 \\
\hline Voluntarily changed place of residence & 12 & 2.1 & 14 & 1.7 & .753 \\
\hline
\end{tabular}




\begin{tabular}{|c|c|c|c|c|c|}
\hline Individual moved out of household & 4 & 0.7 & 9 & 1.1 & .651 \\
\hline Individual moved into household & 8 & 1.4 & 7 & 0.8 & .541 \\
\hline \multicolumn{6}{|l|}{ Other life events } \\
\hline Difficulty getting adequate professional services & 11 & 1.9 & 17 & 2.0 & .852 \\
\hline Victim of crime & 27 & 4.6 & 35 & 4.2 & .799 \\
\hline Became caretaker for relative/friend & 57 & 9.8 & 112 & 13.3 & .101 \\
\hline \multicolumn{6}{|l|}{ Cumulated life events } \\
\hline Mean number of life events +/-SD, range, median & \multicolumn{2}{|c|}{$1.72+/-.08,(0-13), 1$} & \multicolumn{2}{|c|}{$2.13+/-.09,(0-23), 1$} & $<.001 *$ \\
\hline
\end{tabular}

* P-value from chi-squared test or Fisher's exact test

** $\mathrm{P}$-value from t-test. 
Table 3 : Degree of stress and impact on mood related to negative life events, by gender $(\mathrm{N}=1309)$

\begin{tabular}{|c|c|c|c|c|c|c|c|c|c|c|c|c|}
\hline \multirow{3}{*}{ Adverse life events } & \multirow{3}{*}{ Degree of stress } & \multicolumn{2}{|c|}{ Men } & \multicolumn{2}{|c|}{ Women } & \multirow{3}{*}{ P-value } & \multirow{3}{*}{ Impact on mood } & \multicolumn{2}{|c|}{ Men } & \multicolumn{2}{|c|}{ Women } & \multirow{3}{*}{ P-value } \\
\hline & & & & & & & & & & & & \\
\hline & & $\mathrm{n}$ & $\%$ & $\mathrm{n}$ & $\%$ & & & $\mathrm{n}$ & $\%$ & $\mathrm{n}$ & $\%$ & \\
\hline \multicolumn{13}{|l|}{ Financial/work difficulties } \\
\hline & Low & 10 & 23.3 & 6 & 9.0 & ns & Better/much better & 2 & 4.7 & 3 & 4.5 & ns \\
\hline \multirow[t]{3}{*}{ Financial difficulties } & Medium & 14 & 32.6 & 27 & 40.3 & & No change & 9 & 20.9 & 7 & 10.4 & \\
\hline & High & 19 & 44.2 & 34 & 50.8 & & Worse/much worse & 32 & 74.4 & 57 & 85.1 & \\
\hline & Low & 9 & 50.0 & 11 & 73.3 & ns & Better/much better & 3 & 16.7 & 3 & 20.0 & ns \\
\hline \multirow[t]{3}{*}{ Retirement } & Medium & 6 & 33.3 & 1 & 6.7 & & No change & 8 & 44.4 & 5 & 33.3 & \\
\hline & High & 3 & 16.7 & 3 & 20.0 & & Worse/much worse & 7 & 38.9 & 7 & 46.7 & \\
\hline & Low & 1 & 33.3 & 1 & 33.3 & ns & Better/much better & 0 & 0.0 & 0 & 0.0 & ns \\
\hline \multirow[t]{2}{*}{ Loss of employment } & Medium & 1 & 33.3 & 0 & 0.0 & & No change & 1 & 33.3 & 0 & 0.0 & \\
\hline & High & 1 & 33.3 & 2 & 66.7 & & Worse/much worse & 2 & 66.7 & 3 & 100.0 & \\
\hline \multicolumn{13}{|l|}{ Physical illness/accident } \\
\hline & Low & 38 & 40.0 & 57 & 35.0 & ns & Better/much better & 10 & 10.5 & 17 & 10.4 & ns \\
\hline \multirow[t]{3}{*}{ New major physical illness } & Medium & 34 & 35.8 & 52 & 31.9 & & No change & 27 & 28.4 & 27 & 16.6 & \\
\hline & High & 23 & 24.2 & 54 & 33.1 & & Worse/much worse & 58 & 61.1 & 119 & 73.0 & \\
\hline & Low & 38 & 40.0 & 43 & 25.9 & $* * *$ & Better/much better & 11 & 11.6 & 11 & 6.6 & ns \\
\hline
\end{tabular}




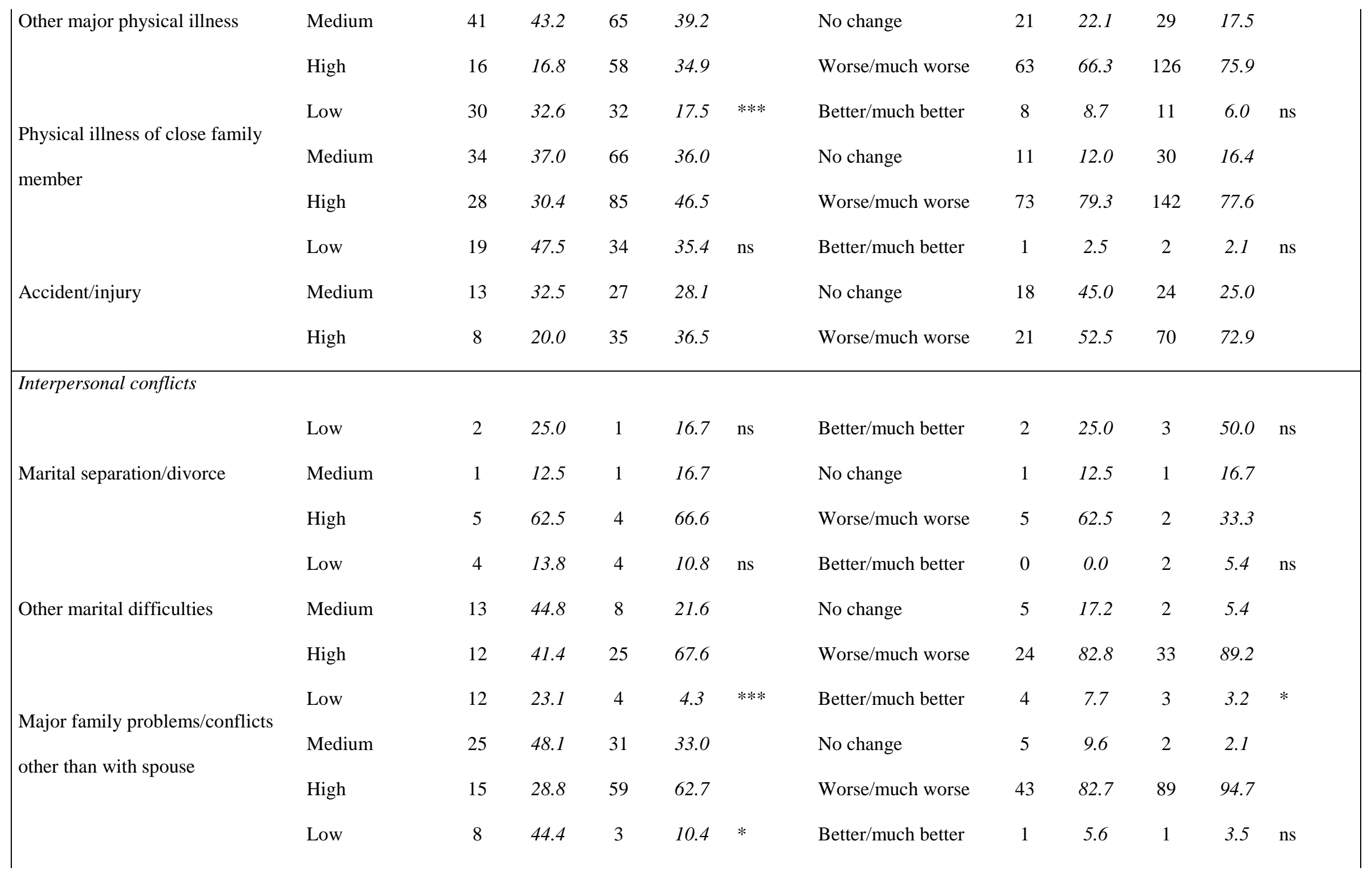




\begin{tabular}{|c|c|c|c|c|c|c|c|c|c|c|c|c|}
\hline Major problems/conflicts with & Medium & 4 & 22.2 & 13 & 44.8 & & No change & 6 & 33.3 & 5 & 17.2 & \\
\hline friends/neighbours & High & 6 & 33.3 & 13 & 44.8 & & Worse/much worse & 11 & 61.1 & 23 & 79.3 & \\
\hline & Low & 3 & 50.0 & 5 & 38.5 & ns & Better/much better & 1 & 16.7 & 4 & 30.7 & ns \\
\hline & Medium & 2 & 33.3 & 2 & 15.4 & & No change & 2 & 33.3 & 1 & 7.7 & \\
\hline & High & 1 & 16.7 & 6 & 46.1 & & Worse/much worse & 3 & 50.0 & 8 & 61.5 & \\
\hline & Low & 3 & 75.5 & 11 & 35.5 & ns & Better/much better & 0 & 0.0 & 3 & 9.7 & ns \\
\hline & Medium & 1 & 25.0 & 9 & 29.0 & & No change & 2 & 50.0 & 4 & 12.9 & \\
\hline & High & 0 & 0.0 & 11 & 35.5 & & Worse/much worse & 2 & 50.0 & 24 & 77.4 & \\
\hline Interpersonal loss & & & & & & & & & & & & \\
\hline & Low & 1 & 33.3 & 3 & 33.3 & ns & Better/much better & 0 & 0.0 & 2 & 22.2 & ns \\
\hline Death of spouse & Medium & 0 & 0.0 & 3 & 33.3 & & No change & 0 & 0.0 & 2 & 22.2 & \\
\hline & High & 2 & 66.7 & 3 & 33.3 & & Worse/much worse & 3 & 100.0 & 5 & 55.6 & \\
\hline & Low & 1 & 33.3 & 0 & 0.0 & ns & Better/much better & 0 & 0.0 & 0 & 0.0 & ns \\
\hline Death of child & Medium & 0 & 0.0 & 0 & 0.0 & & No change & 0 & 0.0 & 0 & 0.0 & \\
\hline & High & 2 & 66.7 & 3 & 100.0 & & Worse/much worse & 3 & 100.0 & 3 & 100.0 & \\
\hline & Low & 6 & 37.5 & 13 & 46.4 & ns & Better/much better & 0 & 0.0 & 4 & 14.3 & ns \\
\hline Death of parent & Medium & 6 & 37.5 & 5 & 17.9 & & No change & 4 & 25.0 & 5 & 17.9 & \\
\hline & High & 4 & 25.0 & 10 & 35.7 & & Worse/much worse & 12 & 75.0 & 19 & 67.9 & \\
\hline
\end{tabular}




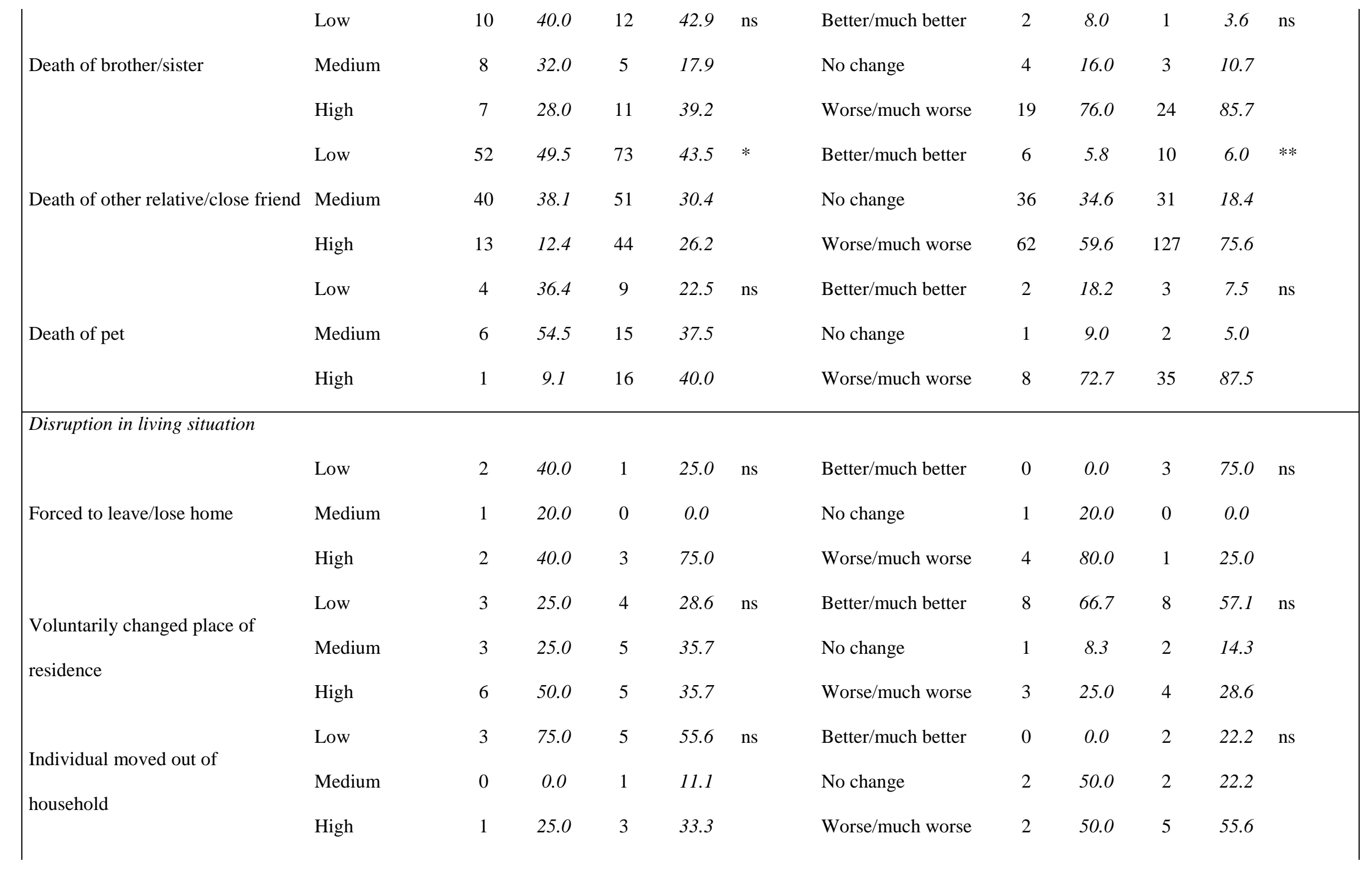




\begin{tabular}{|c|c|c|c|c|c|c|c|c|c|c|c|c|}
\hline \multirow{3}{*}{ Individual moved into household } & Low & 6 & 75.0 & 2 & 28.6 & \multirow[t]{3}{*}{ ns } & Better/much better & 2 & 25.0 & 2 & 28.6 & \multirow[t]{3}{*}{ ns } \\
\hline & Medium & 2 & 25.0 & 5 & 71.4 & & No change & 5 & 62.5 & 4 & 57.1 & \\
\hline & High & 0 & 0.0 & 0 & 0.0 & & Worse/much worse & 1 & 12.5 & 1 & 14.3 & \\
\hline \multicolumn{13}{|l|}{ Other life events } \\
\hline \multirow{4}{*}{$\begin{array}{l}\text { Difficulty getting adequate } \\
\text { professional services }\end{array}$} & Low & 2 & 18.2 & 1 & 5.9 & \multirow[t]{3}{*}{ ns } & Better/much better & 0 & 0.0 & 1 & 5.9 & \multirow[t]{3}{*}{ ns } \\
\hline & Medium & 4 & 36.4 & 4 & 23.5 & & No change & 1 & 9.1 & 2 & 11.8 & \\
\hline & High & 5 & 45.4 & 12 & 70.6 & & Worse/much worse & 10 & 90.9 & 14 & 82.3 & \\
\hline & Low & 8 & 29.6 & 8 & 22.9 & \multirow[t]{3}{*}{ ns } & Better/much better & 0 & 0.0 & 0 & 0.0 & \multirow[t]{3}{*}{ ns } \\
\hline \multirow[t]{2}{*}{ Victim of crime } & Medium & 10 & 37.1 & 8 & 22.9 & & No change & 14 & 51.9 & 12 & 34.3 & \\
\hline & High & 9 & 33.3 & 19 & 54.2 & & Worse/much worse & 13 & 48.1 & 23 & 65.7 & \\
\hline \multirow{3}{*}{$\begin{array}{l}\text { Became caretaker for } \\
\text { relative/friend }\end{array}$} & Low & 30 & 54.5 & 51 & 46.8 & \multirow[t]{3}{*}{ ns } & Better/much better & 12 & 21.8 & 25 & 22.9 & \multirow[t]{3}{*}{ ns } \\
\hline & Medium & 17 & 30.9 & 38 & 34.9 & & No change & 21 & 38.2 & 43 & 39.4 & \\
\hline & High & 8 & 14.6 & 20 & 18.3 & & Worse/much worse & 22 & 40.0 & 41 & 37.6 & \\
\hline \multicolumn{13}{|l|}{ Cumulated life events } \\
\hline \multirow{2}{*}{$\begin{array}{l}\text { Mean level of cumulated stress or } \\
\text { impact }\end{array}$} & \multirow{2}{*}{$\begin{array}{l}\text { Mean level of } \\
\text { stress (SD), } \\
\text { range }\end{array}$} & & .98) & 3.5 & $.98)$ & \multirow{2}{*}{$* * *$} & \multirow{2}{*}{$\begin{array}{l}\text { Mean level of } \\
\text { impact (SD), range }\end{array}$} & & .55) & & 7.0) & \multirow{2}{*}{$* * *$} \\
\hline & & & & & & & & & & & & \\
\hline
\end{tabular}

Explanation: ns: not significant ( $\mathrm{p}>.05),{ }^{*}: \mathrm{p}<.05,{ }^{* *}: \mathrm{p}<.01, * * *: \mathrm{p}<.001$ 
Seematter-Bagnoud L, Karmaniola A, Santos-Eggimann B. Adverse life events among community-dwelling persons aged 65-70 years: gender differences in occurrence and perceived psychological consequences. Social Psychiatry and Psychiatric Epidemiology 2010;45(1):9-16.

Table 4 : Results of multivariate linear regression examining the association between gender and overall life events-related stress and impact

\begin{tabular}{|c|c|c|c|c|c|c|}
\hline \multirow[b]{2}{*}{ Characteristic } & \multicolumn{3}{|c|}{ Life events-related stress } & \multicolumn{3}{|c|}{ Life events-related impact on well-being } \\
\hline & Coefficient & $\begin{array}{c}\text { [95\% confidence } \\
\text { interval] }\end{array}$ & P-value & Coefficient & $\begin{array}{l}\text { [95\% confidence } \\
\text { interval] }\end{array}$ & P-value \\
\hline Female gender & 0.86 & {$[0.46 ; 1.25]$} & $<.001$ & 1.17 & {$[0.47 ; 1.88]$} & .001 \\
\hline Living alone & -0.39 & {$[-0.79 ; 0.01]$} & .056 & -0.39 & {$[-1.10 ; 0.315]$} & .276 \\
\hline Good-very good self-rated health & -1.03 & {$[-1.45 ;-0.61]$} & $<.001$ & -1.93 & {$[-2.67 ;-.1 .18]$} & $<.001$ \\
\hline Depressive symptoms & 2.28 & {$[1.84 ; 2.72]$} & $<.001$ & 3.85 & {$[3.06 ; 4.63]$} & $<.001$ \\
\hline $\begin{array}{l}\text { Two or more chronic diseases } \\
\text { Educational level : }\end{array}$ & 0.64 & {$[0.24 ; 1.04]$} & .002 & 1.11 & {$[0.40-1.82]$} & .002 \\
\hline Compulsory schooling only & - & - & - & - & - & - \\
\hline Apprenticeship & 0.06 & {$[-0.41 ; 0.53]$} & .804 & .23 & {$[-0.61 ; .1 .06]$} & .597 \\
\hline Post-compulsory schooling & 0.60 & {$[0.07 ; 1.12]$} & .026 & 1.34 & {$[0.40 ; 2.28]$} & .005 \\
\hline Tertiary education & 0.71 & {$[0.04 ; 1.38]$} & .035 & 1.39 & {$[0.21 ; 2.58]$} & .021 \\
\hline
\end{tabular}

